\title{
ETNOBOTANI SEBAGAI BAHAN PENYEDAP RASA OLEH MASYARAKAT MELAYU DESA SEJAHTERA MANDIRI KABUPATEN KAPUAS HULU
}

\author{
Megawati Kardina ${ }^{1}$, Elvi Rusmiyanto $\mathbf{P W}^{1}$, Rafdinal $^{1}$ \\ ${ }^{1}$ Program Studi Biologi, Fakultas MIPA, Universitas Tanjungpura, \\ ${ }^{1}$ Prof. Dr. Hadari Nawawi, Pontianak, email, Koresponden: megawatikardina@gmail.com
}

\begin{abstract}
Masyarakat Melayu Desa Sejahtera Mandiri masih memanfaatkan hutan untuk memenuhi kebutuhan seharihari salah satunya yaitu sebagai bahan penyedap rasa. Penelitian ini dilaksanakan selama tiga bulan pada Masyarakat Melayu Desa Sejahtera Mandiri Kabupaten Kapuas Hulu. Metode penelitian menggunakan metode purposive sampling dan teknik semi terstruktur. Data yang diperoleh disajikan menggunakan analisis kuantitatif yaitu dengan menghitung frekuensi sitasi, bagian tumbuhan yang digunakan dan cara pengolahan tumbuhan tertentu yang digunakan dari setiap tumbuhan penyedap rasa. Berdasarkan hasil dari penelitian ditemukan 17 spesies tumbuhan termasuk ke dalam 13 famili yang digunakan sebagai penyedap rasa oleh Masyarakat Melayu Desa Sejahtera Mandiri Kabupaten Kapuas Hulu. Bagian yang digunakan sebagai penyedap rasa yaitu daun $41,17 \%$, buah $29,41 \%$, batang dan umbi $17,64 \%$, rimpang $17,64 \%$, serta biji dan bunga 5,88\%. Cara pengolahan dilakukan dengan cara diiris 58,82\%, digeprek 47,05\%, ditumbuk 41,17\%, diparut $23,52 \%$, diperah dan dikeringkan $17,64 \%$. Tumbuhan yang digunakan sebagai penyedap rasa memiliki nilai frekuensi sitasi tertinggi sebanyak 100,00\% dan nilai terendah 70,00\%.
\end{abstract}

Kata Kunci : Etnobotani, Penyedap Rasa, Masyarakat Melayu, Kapuas Hulu

\section{PENDAHULUAN}

Kalimantan Barat memiliki luas daerah 146.807 $\mathrm{km}^{2}$ dengan luas hutan sebesar $8.356 \mathrm{Ha}$ dan memiliki penduduk sebanyak 4.073.304 jiwa. Masyarakat yang berada di Kalimantan Barat di antaranya suku Dayak, Melayu, Madura, Jawa dan Tionghoa. Kabupaten Kapuas Hulu merupakan kabupaten terluas kedua (setelah Kabupaten Ketapang) di Kalimantan Barat. Luas Kabupaten Kapuas Hulu seluruhnya adalah $31.162 \mathrm{~km}^{2}$. Suku Melayu merupakan suku terbesar kedua dari suku Dayak di Kalimantan Barat dengan jumlah sebanyak 147.543 jiwa (Badan Pusat Statistik, 2015).

Keragaman hayati cukup tinggi di Kalimantan Barat, salah satunya tumbuhan yang dimanfaatkan sebagai penyedap rasa alami pada makanan. Tumbuhan tersebut digunakan sebagai penyedap rasa alami secara turun-temurun oleh masyarakat Melayu dengan tujuan menghasilkan makanan dengan cita rasa yang tinggi. Penyedap rasa alami lebih diminati oleh masyarakat karena lebih aman dikonsumsi dan tidak menimbulkan resiko bagi kesehatan. Penggunaan penyedap rasa sintetik dalam jangka waktu yang panjang dapat menimbulkan resiko bagi kesehatan seperti memicu terjadinya kanker, tekanan darah tinggi, penyakit asma, diabetes, kelumpuhan serta menurunnya kecerdasan pada otak (Nurbani \& Sumarmiyati, 2015).

Hasil Penelitian Afriani, et al., (2007) menyebutkan bahwa masyarakat Dayak disekitar Taman Nasional Kayan Mentarang menggunakan Sengkubak atau sansankng (Pycnarrhena cauliflora) sebagai bahan penyedap rasa alami. Penelitian Juita, et al., (2015) ditemukan 7 jenis spesies tumbuhan seperti Bungkang atau salam (Syzygium polyanthum) yang digunakan oleh suku Dayak Jangkang Tanjung Desa Ribau dan 9 jenis spesies tumbuhan seperti Bunggur seluang (Eurya sp.) yang dipakai oleh suku Melayu Desa Sungai kosak sebagai tumbuhan penyedap rasa alami.

Penelitian tentang penyedap rasa alami di kawasan Desa Sejahtera Mandiri yang masih beragam perlu dilakukan penelitian. Masyarakat suku Melayu Desa Sejahtera Mandiri memiliki adat istiadat yang dilakukan secara turun-temurun dari zaman dahulu. Sejumlah adat istiadat masih lestari di 
Kabupaten Kapuas Hulu, salah satunya dalam acara pernikahan. Nilai-nilai budaya seperti semangat gotong royong dan keagamaan, masih tetap diperhatikan serta budaya memanfaatkan tanaman hutan sebagai bumbu penyedap rasa alami pada makanan seperti Bungkang atau salam (Syzygium polyanthum) masih dipercaya dapat memberikan aroma yang wangi pada makanan. Namun saat ini keberadaan tumbuhan tersebut mulai sulit untuk ditemukan, dikarenakan hutan yang mulai beralih fungsi menjadi hutan perkebunan dan pertambangan. Oleh karena itu perlu dilakukan penelitian di Desa tersebut agar tumbuhan dapat terdokumentasikan.

\section{BAHAN DAN METODE}

\section{Waktu dan Tempat Penelitian}

Penelitian ini dilaksanakan selama 3 bulan yaitu pada bulan Februari sampai April 2018 di Desa Sejahtera Mandiri Kecamatan Hulu Gurung Kabupaten Kapuas Hulu. Tahapan penelitian meliputi pengambilan sampel, pembuatan herbarium, dan identifikasi tumbuhan yang akan dilakukan di Laboratorium Biologi Fakultas Matematika dan Ilmu pengetahuan Alam Universitas Tanjungpura.

\section{Keadaan Umum Lokasi Penelitian}

Desa Sejahtera Mandiri terletak di Kecamatan Hulu Gurung Kabupaten Kapuas Hulu Kalimantan Barat. Utara Desa Sejahtera Mandiri berbatasan dengan Desa Tepuai, sebelah Selatan berbatasan dengan (Desa Tepuai, Landau Kumpang, dan Karya Mandiri), sebelah Timur berbatasan dengan Desa Beringin dan Karya Mandiri, dan sebelah Barat berbatasan dengan Tepuai Kelakar. Luas wilayah Desa Sejahtera Mandiri $1.102 \mathrm{Ha}$, merupakan lahan pertanian $30 \mathrm{Ha}$, wilayah lahan perkebunan $976 \mathrm{Ha}$, serta lahan lainnya $96 \mathrm{Ha}$. Penduduk yang menempati wilayah tersebut berjumlah 403 jiwa dengan jumlah 198 jiwa lakilaki dan 205 jiwa perempuan.

\section{Penentuan Wawancara dan responden}

digunakan, dan metode preparasi tumbuhan didapatkan dengan melakukan wawancara semi Data informasi jenis, habitat, bagian yang terstruktur. Penentuan responden menggunakan metode purposive sampling (Tongco, 2007).

Responden dalam penelitian berjumlah 30 orang dari Suku Melayu Desa Sejahtera Mandiri Kabupaten Kapuas Hulu.

\section{Analisis kuantitatif}

Dilakukan dengan cara menghitung frekuensi sitasi dan bagian tumbuhan yang digunakan dari setiap tumbuhan penyedap rasa oleh Masyarakat Melayu Desa Sejahtera Mandri Kabupaten Kapuas Hulu. Frekuensi sitasi dihitung dengan persamaan sebagai berikut: (Kumar dan Bharati, 2014)

$$
\text { Frekuensi sitasi }(\%)=(\mathrm{N} / \mathrm{T}) \times 100 \%
$$

\section{Keterangan:}

$\mathrm{N}$ : Jumlah responden yang mensitasi

$\mathrm{T}:$ Jumlah total responden

Presentase Bagian dan cara pengolahan tumbuhan dihitung dengan rumus:

Bagian Tumbuhan $=\frac{\sum \mathrm{x}}{\Sigma \mathrm{y}} \mathrm{x} 100 \%$

Cara Pengolahan Tumbuhan $=\frac{\Sigma \mathrm{X}}{\Sigma \mathrm{y}} \times 100 \%$

Keterangan:

$\mathrm{x}=$ Jenis tumbuhan yang menggunakan bagian tertentu, $\mathrm{y}=$ Jenis tumbuhan yang ditemukan, $\mathrm{X}=$ Cara

pengolahan tumbuhan tertentu.

\section{HASIL DAN PEMBAHASAN}

\section{Hasil}

Hasil penelitian menunjukkan bahwa masyarakat Melayu Desa Sejahtera Mandiri menggunakan 17 spesies tumbuhan yang termasuk dalam 13 famili sebagai bahan penyedap rasa Jenis tumbuhan tersebut dapat dilihat pada Tabel 1. 
Tabel 1 Spesies Tumbuhan dan Frekuensi Sitasi Tumbuhan Penyedap Rasa oleh Masyarakat Melayu Desa Sejahtera Mandiri

\begin{tabular}{|c|c|c|c|c|}
\hline \multirow{2}{*}{ No } & \multirow{2}{*}{ Famili } & \multicolumn{2}{|c|}{ Jenis Tumbuhan Penyedap Rasa } & \multirow{2}{*}{$\begin{array}{l}\text { Frekuensi } \\
\qquad(\%)\end{array}$} \\
\hline & & Nama Ilmiah & Nama Lokal & \\
\hline 1 & Arecaceae & Cocos nucifera $L$. & Nyiur & 100,00 \\
\hline \multirow[t]{2}{*}{2} & Liliaceae & Allium cepa $L$. & Bawang merah & 100,00 \\
\hline & & Allium sativum $L$. & Bawang putih & 100,00 \\
\hline 3 & Manispermaceae & Pycnarrhena cauliflora (Miers) Diels & Sengkubak & 100,00 \\
\hline 4 & Myrtaceae & Syzygium polyanthum Wigh Walp & Bungkang & 100,00 \\
\hline 5 & Oxalidaceae & Averrhoa bilimbi $L$. & Belimbin buluh & 63,33 \\
\hline 6 & Pandanaceae & Pandanus amaryliflora Roxb. & Pandan & 100,00 \\
\hline 7 & Piperaceae & Piper nigrum L. & Sahang & 86,66 \\
\hline 8 & Poaceae & Cymbopogon citrates (DC) Stapf & Serai & 100,00 \\
\hline 9 & Polygonaceae & Polygonum minus & Kesum & 83,33 \\
\hline 10 & Rhizophoraceae & Carallia brachiata Merr. & Kanis & 100,00 \\
\hline 11 & Rutaceae & Citrus aurantifolia Swingle. & Limau & 70,00 \\
\hline 12 & Solanaceae & Capsicum frutescens $L$. & Cabik rawit & 73,33 \\
\hline \multirow[t]{4}{*}{13} & Zingiberaceae & Alpinia galanga $S W$. & Lengkuas & 100,00 \\
\hline & & Curcuma domestica Valeton & Kunyit & 100,00 \\
\hline & & Etlingera elatior (Jack) & Simpur & 100,00 \\
\hline & & Zingiber officinale Rosc. & Jahe & 100,00 \\
\hline
\end{tabular}

Berdasarkan analisis kuantitatif, spesies tumbuhan yang digunakan sebagai penyedap rasa oleh Masyarakat Melayu Desa Sejahtera Mandiri diperoleh 17 spesies tumbuhan yang termasuk ke dalam 13 famili dengan nilai frekuensi sitasi terbanyak hingga paling sedikit. Spesies tumbuhan yang memiliki nilai tertinggi sebanyak 100,00\% dan Tumbuhan yang paling sedikit disitasi berasal dari famili Oxalidaceae yaitu Tumbuhan Averrhoa bilimbi L. dengan nilai frekuensi sitasi sebanyak $63,33 \%$.

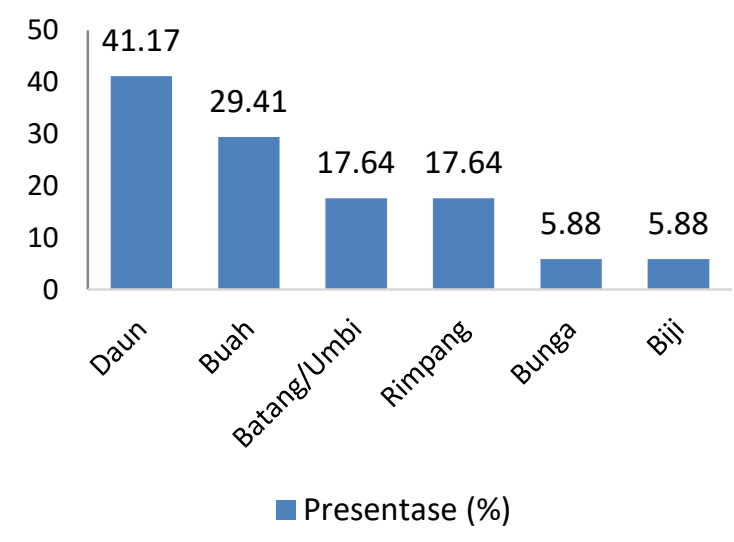

Gambar 1. Diagram Persentase bagian Tumbuhan yang digunakan sebagai Bahan Penyedap Rasa oleh Masyarakat Melayu Desa Sejahtera Mandiri.
Berdasarkan gambar 1 diagram persentase bagian tumbuhan penyedap rasa oleh Masyarakat Melayu Desa Sejahtera Mandiri yang paling banyak digunakan adalah bagian daun dengan persentasenya sebesar $41,17 \%$, bagian buah dengan sebesar 29,41\%, bagian batang, umbi dan rimpang sebesar 17,64\%. Bunga dan biji sebesar $5,88 \%$.

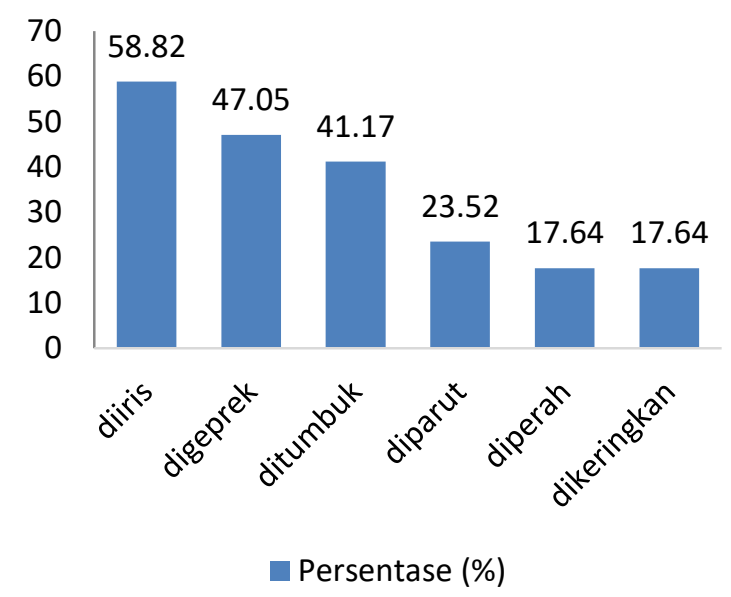

Gambar 2. Diagram Persentase Cara Pengolahan Tumbuhan Penyedap Rasa oleh Masyarakat Melayu Desa Sejahtera Mandiri. 
Pengolahan tumbuhan yang digunakan sebagai bahan penyedap rasa yaitu dengan cara diiris, digeprek, ditumbuk, diparut, diperah dan dikeringkan. Persentase cara pengolahan tumbuhan dengan cara diiris sebanyak 58,82\%, digeprek $47,05 \%$, ditumbuk $41,17 \%$, diparut $23,52 \%$, diperah dan dikeringkan dengan persentase yang sama sebanyak $17,64 \%$.

\section{PEMBAHASAN}

Berdasarkan hasil wawancara dengan Masyarakat Melayu Desa Sejahtera Mandiri Kabupaten Kapuas Hulu, tumbuhan yang digunakan sebagai penyedap rasa ditemukan 17 spesies dari 13 famili tumbuhan.

Nilai frekuensi sitasi $100,00 \%$ dikarenakan tumbuhan tersebut merupakan bahan pangan sehari-hari yang umum dimanfaatkan oleh Masyarakat dan masih dapat ditemukan dengan mudah. Nilai frekuensi sitasi terendah yang ditemukan pada Masyarakat Melayu Desa Sejahtera Mandiri Kabupaten Kapuas Hulu yaitu $63,33 \%$, terdapat pada tumbuhan A. Bilimbi karena tumbuhan tersebut sudah jarang digunakan dan spesies tumbuhan tersebut sudah sulit ditemukan didaerah tersebut.

Menurut Kumar dan Bharati (2014), menyatakan bahwa spesies yang paling populer atau umum digunakan oleh masyarakat akan mendapatkan jumlah tertinggi untuk kutipan frekuensi sitasinya. Spesies yang memiliki nilai frekuensi yang tinggi menunjukan spesies tersebut masih sering digunakan dan nilai frekuensi yang rendah menunjukkan bahwa spesies tersebut sudah jarang digunakan.

Masyarakat Melayu Desa Sejahtera Mandiri Kabupaten Kapuas Hulu dalam memanfaatkan spesies tumbuhan tertentu yang digunakan sebagai penyedap rasa dibuktikan dengan adanya beberapa penelitian yang menyatakan bahwa tumbuhan tersebut memiliki potensi sebagai penyedap rasa. Penelitian Wibowo (2006) menyatakan bahwa $A$. sativum mempunyai suatu ciri khas yaitu aromanya yang mampu memberikan cita rasa sangat khas yang ditimbulkan oleh komponen sulfur yang ada pada minyak volatin. Jenis senyawa yang menentukan bau khas A. sativum yaitu Alliin, yang terurai apabila dimemarkan dan memberikan aroma wangi dan sebagai antibakteri.
Hasil wawancara, bagian-bagian tumbuhan yang digunakan oleh Masyarakat Melayu Desa Sejahtera Mandiri adalah daun, umbi/batang, bunga, rimpang, buah dan biji. Bagian tumbuhan yang paling sering digunakan adalah daun dengan persentase $41,17 \%$, buah $29,41 \%$, batang/umbi dan rimpang $17,64 \%$, sedangkan bagian yang paling sedikit digunakan adalah bunga dan biji yaitu sebesar 5,88\% (Gambar 1). Menurut Juita (2015), Penggunaan bagian daun sebagai penyedap rasa dikarenakan bagian tersebut berpotensi memberikan rasa manis pada masakan, terutama pada bagian daun muda rasa manis yang ditimbulkan sangat terasa, sehingga mampu memberikan rasa manis pada masakan dan menghilangkan rasa pahit yang biasa ditimbulkan oleh sayur-sayuran tertentu.

Pengolahan tumbuhan sebagai penyedap rasa oleh Masyarakat Melayu Desa Sejahtera Mandiri yang paling banyak yaitu diiris dengan persentasenya sebanyak 58,82\%\%, digeprek dengan persentasenya sebanyak $47,05 \%$, ditumbuk dengan persentasenyase banyak sebanyak $41,17 \%$, diparut dengan persentasenya sebanyak $23,52 \%$, diperah dan dikeringkan dengan persentase yang sama sebanyak 17,64\% (Gambar 2).

Pengolahan tumbuhan yang digunakan sebagai bahan penyedap rasa yaitu dengan cara diiris, digeprek, ditumbuk, diparut, diperah dan dikeringkan. Pengolahan tumbuhan penyedap rasa dengan cara diiris digunakan oleh Masyarakat Melayu Desa Sejahtera Mandiri yaitu berasal dari tumbuhan A. cepa, A. sativum, A. galangal, A. bilimbi, C. Brachiata, C. frutescens, C. Domestica, E. elatior, P. minus dan Z. officinal.

Pengolahan tumbuhan penyedap rasa dengan cara digeprek digunakan oleh Masyarakat Melayu Desa Sejahtera Mandiri yaitu berasal dari tumbuhan $A$. galangal, $C$. aurantifolia, $C$. domestica, $C$. citrares, $P$. amarylifolius, $P$. cauliflora, $S$. polyanthum dan $Z$. Officinale. Pengolahan tumbuhan penyedap rasa dengan cara ditumbuk digunakan oleh Masyarakat Melayu Desa Sejahtera Mandiri yaitu berasal dari tumbuhan A. cepa, A. sativum, A. galangal, C. frutescens, $C$. domestica, $P$. nigrum dan Z. officinale. 
Pengolahan tumbuhan penyedap rasa dengan cara diparut digunakan oleh Masyarakat Melayu Desa Sejahtera Mandiri yaitu berasal dari tumbuhan $C$. nucifera, A. galangal, C. domestica, Z. officinale. Pengolahan tumbuhan penyedap rasa dengan cara diperah oleh Masayarakat Melayu Desa Sejahtera mandiri yaitu berasal dari tumbuhan A. bilimbi, $C$. aurantifolia dan $C$. nucifera. Pengolahan tumbuhan penyedap rasa dengan cara dikeringkan oleh Masyarakat Melayu Desa Sejahtera Mandiri yaitu berasal dari tumbuhan $C$. Brachiata, $P$. cauliflora, dan S. polyanthum.

\section{DAFTAR PUSTAKA}

Afriani, U R, 2007, Kajian Etnobotani dan Aspek Konservasi Sengkubak (Pcynarrhena cauliflora (Miers.) Diels.) di Kabupaten Sintang Kalimantan Barat, Tesis sekolah Pascasarjana IPB, Bogor.

Badan Pusat Statistik, 2015, Kalimantan Barat dalam Angka, BPS Kalimantan Barat.

Juita, 2015, Pemanfaatan Tumbuhan Sebagai Penyedap Rasa Alami Pada Masyarakat Suku Dayak Jangkang Tanjung dan Melayu Di Kabupaten Sanggau, Fakultas Matematika dan Ilmu Pengetahuan Alam Universitas Tanjungpura, Pontianak.

Kumar, R, dan Bharati, KA, 2014, Etnomedicines of Tharu Tribes of Dudhwa National Park, India, Ethnobotany Reserch and Applications, vol. 2, no.001, hal. 1-3.

Nurbani dan Sumarmiyati, 2015, Eksplorasi dan Karakterisasi Tumbuhaan Mekai sebagai Penyedap Rasa di kabupaten Bulungan, Provinsi kalimantan Utara, Pros SemNas Massy BiodivIndon, Vol. 1, No. 2, Hal. 201206.

Tongco, D.C, 2007, Purposive Sampling as a Tool for Informant Selection. Ethnobotany Research \& Applications5:147-158.

Wibowo S, 2006, Budidaya Bawang, Bawang Putih, Bawang Merah, Bawang Bombay, Jakarta, Penebar Swadaya, hal 80-81. 